\title{
Optimally Differentiated Carbon Prices for Unilateral Climate Policy
}

Stefan Boeters 



\title{
Optimally Differentiated Carbon Prices for Unilateral Climate Policy
}

\author{
Stefan Boeters* \\ CPB, Netherlands Bureau for Economic Policy Analysis, Den Haag
}

July 2014

\begin{abstract}
Economic thought on climate policy as an instance of environmental regulation is strongly influenced by the principle of a uniform carbon price. Economists acknowledge that this principle breaks down in a "second-best" world with other distortions, such as taxes and market power in domestic and international markets. However, systematic analysis of this point in the economic climate policy literature is scarce. In the present paper, a computable general equilibrium (CGE) set-up is chosen in order to examine what pattern of differentiated carbon prices emerges as optimal in a second-best world.

The CGE model WorldScan, which is considered to be representative of the class of models routinely used for numerical climate policy analysis, produces three main results: First, the optimal pattern of carbon prices is highly differentiated, ranging from almost prohibitive taxes to high subsidies (with a range of more than 1700 euros per ton of $\mathrm{CO}_{2}$ ). Second, the welfare gain from switching from a uniform price to optimally differentiated prices is enormous, equivalent to a $27 \%$ emission reduction for free. Third, the most important drivers of carbon price differentiation are market power in export markets as well as taxes on consumption, intermediate inputs and domestic output. This shows that carbon price differentiation cannot be dismissed as a policy option lightly. However, before translating these findings into concrete policy advice, the relevant features of modelling pre-existing distortions in CGE models need close revision.
\end{abstract}

Keywords: climate policy, uniform carbon price, carbon price differentiation, optimal taxation, computable general equilibrium model

JEL codes: Q42, Q54, H21, H23, D58

*Stefan Boeters, CPB, P.O. Box 80510, NL-2508 GM Den Haag, e-mail: s.boeters@cpb.nl. I thank Johannes Bollen, Corjan Brink, Paul Veenendaal, Herman Vollebergh and two reviewers of this journal for helpful discussion and suggestions. 


\section{Introduction}

If one tenet in environmental economics has over gained a mantra-like status over the years, it is that of "uniform emission pricing". Theorists have shown that the differentiation of emission prices across time, space or type of emission source makes abatement unnecessarily expensive. Policy advisers - most prominently in climate policy - echo this insight by advocating emission trade schemes that are as encompassing as possible, with a maximum of "where", "when" and "what" flexibility.

Of course, no environmental economist is as naive as to claim that the "Law of Uniform Emission Pricing" holds in a strict sense. After all, the general optimism in formulating law-like tenets for public policy has been decisively tempered ever since the "General Theory of Second Best", which essentially claims the absence of a general theory for second-best situations (Lipsey and Lancaster, 1956). This is because other distortions in the economy, such as externalities that have been incompletely internalised, a multitude of partial and indirect internalisation options emerge. Indeed, once emission prices are seen as instruments not only for reducing emissions in general, but also for correcting all kinds of pre-existing distortions in the economy, it would be careless to presuppose that a uniform emission price should be the norm.

Even though most environmental economists would readily subscribe to the long list of caveats that accompany the Law of Uniform Emission Pricing, these caveats rarely play a noticeable role in concrete policy advice. Explicitly or - most of the time - implicitly, environmental economists as policy advisers assume that even if the Law of Uniform Emission Pricing is only an approximation of optimal climate policy, it remains a good approximation. The implicit assumption is that if we were able to calculate optimally differentiated carbon prices, these would deviate little from a uniform price, and the welfare loss from applying such a uniform price instead of optimally differentiated pricing would be small.

Only a small number of theoretical studies explore the case for carbon price differentiation in analytical models (Markusen, 1975; Hoel, 1996). These studies confirm the general second-best result of Lipsey and Lancaster (1956) in the specific setting of emission reduction: once other distortions are present, the simple rules 
for optimal policy do not apply any more. However, the analytical expressions that characterise the optimum in a second-best model quickly become so complicated that it is difficult to tell even the direction of the deviation. Formulas that would be informative about the costs of deviating from the optimum are even more complex and thus scarcely derived in previous analytical papers.

The appropriate follow-up in situations where analytical expressions no longer lend themselves to interpretation is numerical modelling. Surprisingly, to my knowledge only a single paper addresses carbon price differentiation numerically, namely the paper by Böhringer, Lange and Rutherford (2014). ${ }^{1}$ For two regions, the EU and and the US, these authors explore whether carbon price differentiation raises welfare. However, they account for a single degree of freedom only. The unilaterally abating region may use two carbon prices for energy-intensive industries and the rest of the economy. In this restricted setting, two incentives for carbon price differentiation are distinguished and explored, namely the strategic use of market power in international trade (terms-of-trade effects) and compensation for leakage. The overall conclusion drawn by Böhringer et al. (2014, p. 2) is that the differentiation in carbon prices that can be motivated by such market imperfections is moderate and that the welfare gain attainable by exploiting carbon price differentiation is negligible.

The conclusions drawn from the simulations with the computable general equilibrium (CGE) model WorldScan in this paper are strikingly different from those in Böhringer et al. (2014). By solving for welfare-maximising differentiated carbon prices, I obtain widely diverging prices that range from high subsidies to virtually prohibitive taxes. I also show that huge welfare gains are possible by exploiting the implied inefficiencies of a uniform carbon price. These gains are equivalent to a $27 \%$ reduction in carbon emissions for free. However, these results should not be misunderstood as direct policy advice. In the body of this paper, I decompose the effects at work and explain their components as far as possible, but many questions remain unanswered. The presented findings are best understood as a counterpoint to Böhringer et al.'s (2014) message that carbon price differentiation is almost irrel-

\footnotetext{
${ }^{1}$ Actually, Markusen (1975) backs up his argument with numerical simulations as well. However, in these simulations he simply compares different policy mixes, without determining an optimum. Recently, Böhringer and Alexeeva-Talebi (2012) used a similar set-up to that presented in Böhringer et al. (2014) to study competitiveness issues.
} 
evant. They mark the range of possible model results and call for more contributions by applied modellers.

From the set-ups of these two studies (Böhringer et al., 2014, and the present paper), two clear candidates for explaining the differences in the model results emerge. First, in the simulations of the present paper, carbon prices are allowed to vary in two dimensions, by sector and by fuel, in considerable sectoral detail. It turns out that "energy-intensive" versus "non-energy-intensive" is not a good discrimination criterion for high versus low carbon prices. Second, WorldScan, the model used in the present study, contains the full range of tax distortions captured by the GTAP data set (input taxes, output taxes, consumption taxes and tariffs in international trade). These were neglected in Böhringer et al.'s (2014) study. ${ }^{2}$ I show that pre-existing intermediate input taxes, consumption taxes and output taxes are particularly important drivers of differentiation in the pattern of optimal carbon prices.

The remainder of this paper is organised as follows. In Section 2, the model and scenario settings are introduced. Section 3 presents the simulations with the derivation of optimally differentiated carbon prices and the decomposition into driving forces (pre-existing distortions). Section 4 shows in an explorative and exemplary fashion how the model results change once we deviate from the conventional modelling practice of conceptualising pre-existing taxes as pure distortions. Section 5 contains a summary and concludes.

\section{Model and scenarios}

\subsection{CGE model: WorldScan}

WorldScan, the model used for the quantitative simulations, is similar to a number of other CGE models used on a regular basis to assess world-wide climate policy (e.g. MIT-EPPA; Paltsev et al., 2005). It is a multi-region, multi-sector, recursively dynamic CGE model based on the GTAP7 data set (Badri and Walmsley, 2008)

\footnotetext{
${ }^{2}$ Böhringer et al. (2014) are not explicit about this. However, it is implied by the fact that uniform carbon prices are actually optimal in their model when carbon leakage and terms-of-trade effects are switched off (Scenario "None", p. 15).
} 
with the base year 2004. ${ }^{3}$ The details of the model are described in Lejour et al. (2006). Here we use an extension with a bottom-up representation of the electricity sector, as documented in Boeters and Koornneef (2011).

The aggregation of regions and sectors can be flexibly adjusted in WorldScan. I use a version with nine regions and sixteen sectors, as listed in Tables 1 and 2. Regional disaggregation is relatively coarse, the EU - as the proponent of unilateral climate policy in the presented simulations - is treated as one homogeneous region. ${ }^{4}$ Sectoral disaggregation has a focus on the energy-related sectors, whereas other sectors are captured in a more aggregated manner. The electricity sector has a bottom-up structure, namely five separate technologies with increasing marginal costs, whose output is perfectly substitutable (see Table 3 and Boeters and Koornneef, 2011).

Table 1: Regions in WorldScan

\begin{tabular}{ll}
\hline \hline European Union & USA \\
Other OECD & Brazil \\
China & India \\
Other SE Asia & Former Soviet Union \\
Rest of the World & \\
\hline \hline
\end{tabular}

The discussion of carbon price differentiation below is in terms of "carbon sources". Sixteen sectors plus final consumption (FCN) times three fuels (coal, natural gas and petroleum products) results in 51 potential sources of $\mathrm{CO}_{2}$ emissions. All sources that have a share of less than $0.1 \%$ of total emissions are disregarded in the simulation. The remaining 36 sources cover $99.6 \%$ of all baseline emissions in 2020, with the largest shares in the electricity generation, transport and refinery sectors (see Table 4). The fuel split of the 36 sources analysed is nine for coal, thirteen for gas and fourteen for petroleum products. Two sectors (i.e., COA and OIL) completely disappear from the analysis, because none of their sources is above the critical level.

\footnotetext{
${ }^{3}$ During the course of the project, the GTAP8 data set (base year 2007) became available. However, as the point of the present paper is a rather general one and not dependent on the details of the initial situation, there is no particular value added from updating the data base adopted.

${ }^{4}$ Determining the optimal regional differentiation of carbon prices within Europe would add a further dimension to the problem; however, this is outside the scope of the present paper.
} 
Table 2: Sectors in WorldScan

\begin{tabular}{llll}
\hline \hline AFF & Agriculture, forestry, fishing & COA & Coal \\
OIL & Oil & GGD & Gas and gas distribution \\
CNP & Consumer products & PPP & Paper products and publishing \\
PCP & Petroleum and coal products & CRP & Chemical, rubber, plastic products \\
MMP & Minerals and mineral products & MET & Metals \\
CGD & Capital goods and durables & ELY & Electricity \\
RRT & Road and rail transport & WTP & Water transport \\
ATP & Air transport & NTS & Non-transport services \\
\hline \hline
\end{tabular}

Table 3: Baseline: EU electricity production

\begin{tabular}{lcc}
\hline \hline Generation technology & Share (\%) in 2004 & Share (\%) in 2020 \\
\hline Fossil & 62.6 & 66.5 \\
Nuclear & 23.1 & 20.4 \\
Hydropower & 7.6 & 6.8 \\
Wind \& sun & 2.1 & 2.1 \\
Biomass & 4.5 & 4.1 \\
\hline \hline
\end{tabular}

\subsection{Market distortions}

WorldScan includes a number of taxes, which cause deviations of the prices from marginal costs. ${ }^{5}$ For the simulations of this paper, the most important of these taxes are taxes on intermediate inputs in production, sectoral ouput taxes and consumption taxes differentiated by commodity. Together with market power on the input and export markets, these distortions turn out to be drivers of the differentiation in optimal cabon prices and are therefore the focus of the decomposition exercise in Sections 3.2.1 and 3.2.2.

In addition, WorldScan contains five smaller distortions, which must be removed in order to arrive at a clear-cut first-best world. This set of smaller distortions consists of imperfect capital mobility, endogenous international transfers and three further taxes: on imports, exports and investment. The effect of these minor distor-

\footnotetext{
${ }^{5}$ All tax rates except carbon prices are assumed to be fixed in the study of the present paper. Therefore it cannot be characterized as falling into the "second best" literature as defined by Baumol and Bradford (1970). The latter would require joint optimisation of all taxes.
} 
Table 4: Emission sources in the EU (\% in total $\mathrm{CO}_{2}$ emissions)

\begin{tabular}{lccc}
\hline \hline & Coal & Natural gas & Petroleum prod. \\
\hline AFF & - & 0.2 & 1.1 \\
COA & - & - & - \\
OIL & - & - & - \\
GGD & - & 0.2 & - \\
CNP & 0.2 & 1.2 & 0.6 \\
PPP & 0.1 & 0.6 & 0.2 \\
PCP & 4.8 & 1.1 & 7.7 \\
CRP & 0.2 & 2.0 & 5.0 \\
MMP & 0.6 & 1.3 & 1.2 \\
MET & 0.2 & 0.8 & 0.9 \\
CGD & - & 0.8 & 0.4 \\
ELY & 21.1 & 6.7 & 2.2 \\
RRT & - & 0.2 & 12.6 \\
WTP & - & - & 2.0 \\
ATP & - & - & 3.7 \\
NTS & 0.1 & 2.8 & 2.3 \\
FCN & 0.5 & 5.4 & 8.8 \\
\hline \hline
\end{tabular}

tions on the pattern of optimal carbon prices is negligible, however. The last tax included in WorldScan, the income tax on labour earnings, amounts to lump-sum taxes without any distortionary effect because labour supply is fixed.

\subsection{Baseline}

WorldScan is set up to analyse deviations from a baseline ("business as usual") path. This path is not generated by WorldScan itself, but derived from other models or scenario studies. In the present case, the baseline is taken from the Environmental Outlook 2008 scenario generated with the TIMER model of the Netherlands Environmental Assessment Agency (OECD, 2008), updated for growth changes throughout the global credit crisis of 2009/2010.

The baseline calibration uses time series for population and GDP by region, energy use by region and energy carrier, and world fossil fuel prices by energy carrier. Population is an exogenous input into the model. The other time series are re- 
Table 5: Baseline in 2020: Quantities and prices

\begin{tabular}{lcc}
\hline \hline Economic indicators & $\begin{array}{c}\text { 2020 value as a } \\
\text { multiple of 2004 }\end{array}$ & $\begin{array}{c}\text { Yearly growth } \\
\text { 2004-2020 }(\%)\end{array}$ \\
\hline Population & 1.051 & 0.3 \\
Real GDP & 1.281 & 1.6 \\
Fossil energy use & 0.975 & -0.2 \\
$\quad$ Oil & 0.980 & -0.1 \\
$\quad$ Natural gas & 0.964 & -0.2 \\
$\quad$ Coal & 0.979 & -0.1 \\
Electricity use & 1.123 & 0.7 \\
CO $_{2}$ emissions & 0.973 & -0.2 \\
Fossil energy intensity & 0.761 & -1.7 \\
Fossil energy prices & & \\
$\quad$ Oil & 2.046 & 4.6 \\
$\quad$ Natural gas & 1.737 & 3.5 \\
Coal & 1.734 & 3.5 \\
\hline \hline
\end{tabular}

produced by adjusting the corresponding model parameters. These are total factor productivity (differentiated by sector) for GDP, autonomous energy efficiency for energy quantities, and the amount of natural resources available as an input into fossil fuel production for energy prices.

Table 5 lists important baseline indicators for the EU in 2020 (relative to 2004). The mix of fossil fuels remains roughly stable, while total $\mathrm{CO}_{2}$ emissions are decreasing by $0.2 \%$ per year. The latter is a consequence of the falling energy intensity of the economy, driven by a shift away from the most energy-intensive sectors. The bottom rows of Table 5 show the underlying real fuel prices (relative to the EU consumption price index). Relative fuel prices remain stable, whereas the overall increase in the fossil fuel price level contributes to the reduction in energy intensity. ${ }^{6}$

\footnotetext{
${ }^{6}$ Appendix A.1 shows the results for a different set of baseline assumptions, which were used in an earlier version of this paper. It turns out that these assumptions hardly affect the pattern of optimally differentiated carbon prices.
} 


\subsection{Scenarios}

All scenarios examined in Section 3 are unified by a EU reduction target for $\mathrm{CO}_{2}$ emissions in 2020 of $20 \%$ of their baseline level. ${ }^{7}$ The simulations are carried out for the year 2020 only, assuming a smooth adjustment path in the years before. I compare the reference case of a uniform emission price with the case of emission prices that are optimally differentiated across fuels and sectors. An important part of the body of the paper consists of decomposition scenarios. In these scenarios, all distortions except one are eliminated from the model. This approach can determine the degree of carbon price differentiation that can be justified by one distortion alone. The decomposition also allows us to ascertain which distortions are driving the results, and which lead to only minor adjustments.

Finally, in Section 4, two additional scenarios follow that can be read as a - albeit partial - sensitivity analysis. In these scenarios, I interpret excise taxes on fossil fuels as a joint input into the consumption of transport services, rather than as a pure distortion. In this way, it is clarified that there is scope for the interpretation of the tax figures in the data, which has consequences for the structure of optimally differentiated carbon prices.

\subsection{Numerical procedure}

The model WorldScan is set up as a mixed complementarity problem (Rutherford, 1995) and can therefore not be maximised in a straightforward way. Ferris et al. (2005) report a certain progress in the numerical treatment of maximisation problems with complementarity constraints. However, this has not reached the stage of application to large-scale CGE models yet. Another option would be to eliminate the complementarity constraints in the model (which are located exclusively in the renewable energy sector and not likely to affect the overall results significantly) and solve the model as a constraint nonlinear maximisation problem. Given the large

\footnotetext{
${ }^{7}$ This setting is inspired by the model comparison exercise in Round 22 of the Energy Modeling Forum (Böhringer et al., 2009). Because the "20/20/20" target of the EU is a heavily researched scenario, it seems an appropriate setting to place the simulations in the present paper into perspective. The official EU reduction targets are defined relative to historical 1990 emissions, whereas in the model, they are relative to the baseline, which deviates only slightly from the 1990 level.
} 
number of degrees of freedom and the flatness of the objective function, this is not likely to work numerically.

Therefore, I employ the following iterative procedure to determine the optimally differentiated carbon prices:

1. Solve the model for the uniform carbon price that implements the required emission reduction.

2. Add a small disturbance to the uniform carbon price (or a proportional disturbance to all differentiated prices in later iterations), solve the model and calculate the marginal welfare costs of emission reduction from this.

3. Solve the model repeatedly with small disturbances for each of the carbon prices at the individual sources. Use the results to calculate numerically the first and second order derivations of the welfare function and the emission function and, by division, the marginal welfare cost of emission reduction at a specific source.

4. If the welfare costs have converged across all sources then a solution is found. (In my simulations, I used a tolerance bound of $1 € / \mathrm{tCO}_{2}$.)

5. Calculate new guesses for each of the individual carbon prices by using the derivatives calculated in Step 3 to adjust prices so that their expected marginal welfare cost equal the marginal welfare cost calculated in Step 2.

6. Solve the model with the new carbon prices. The solution will in general not meet de overall emission reduction restriction. Add a proportional correction term to all carbon prices to account for this deviation.

7. Return to Step 2 and iterate until a solution is found in Step 4.

In essence, this is a simplified Newton-Raphson method, which neglects cross-derivatives. As such, it does not warrant convergence. However, in the concrete cases of this paper, convergence is always achieved. Depending on the scenario, it can require up to 50 iterations until marginal welfare costs are equalised across emission sources. 


\section{Results}

\subsection{Optimally differentiated $\mathrm{CO}_{2}$ prices}

The point of departure for the simulations is the projected baseline situation in 2020 (see Figure 5). As the reference case, I simulate a $20 \%$ reduction in $\mathrm{CO}_{2}$ emissions with respect to the baseline in the $\mathrm{EU}$, implemented by a uniform carbon price across all sources (sectors and fuels). This uniform carbon price turns out to be 14 euros per ton of $\mathrm{CO}_{2} \cdot{ }^{8}$ The motivating question of the present paper is whether we can improve upon this situation by differentiating carbon prices by source.

As a first indication of whether the uniform price is close to, or far away from, the optimum under price differentiation, I calculate the marginal welfare cost of the emission price by source. This calculation is carried out by increasing the emission price for one source, and holding the prices of all other sources fixed, and then repeating for each of the analysed sources. The resulting welfare change (Hicksian equivalent variation for the change in the consumption of the representative EU consumer) is divided by the resulting overall change in emissions (from all sources together). The result has the same dimension as the carbon prices, euros per ton of $\mathrm{CO}_{2}$. Figure 1 shows the marginal welfare costs for the 36 largest sources, which cover more than $99.6 \%$ of all emissions (see Section 2). As also noted earlier, two sectors (i.e., COA and OIL) completely disappear from the graph, because none of their sources is above the critical level.

The range of marginal welfare costs is huge. Welfare costs are highest for petroleum and coal products (PCP) in minerals and mineral products (MMP) with $558 \mathrm{e} / \mathrm{tCO}_{2}$ and lowest, even negative, for PCP in water transport (WTP) with $-300 € / \mathrm{tCO}_{2}$. For several other sources the marginal welfare costs are negative as well, even if only slightly so. Negative welfare costs mean that reducing $\mathrm{CO}_{2}$ for the respective sources would increase economic welfare. The overall range of marginal welfare costs is more than $850 € / \mathrm{tCO}_{2}$, indicating a huge potential for welfare gains through carbon price differentiation.

\footnotetext{
${ }^{8}$ This is close to the price of 17 euros calculated in Boeters and Koornneef (2011) under slightly different assumptions. The WorldScan emission prices are often at the lower end of the spectrum of the results from similar models (compare the results in Böhringer et al., 2009).
} 
Figure 1: Marginal costs of the uniform emission price

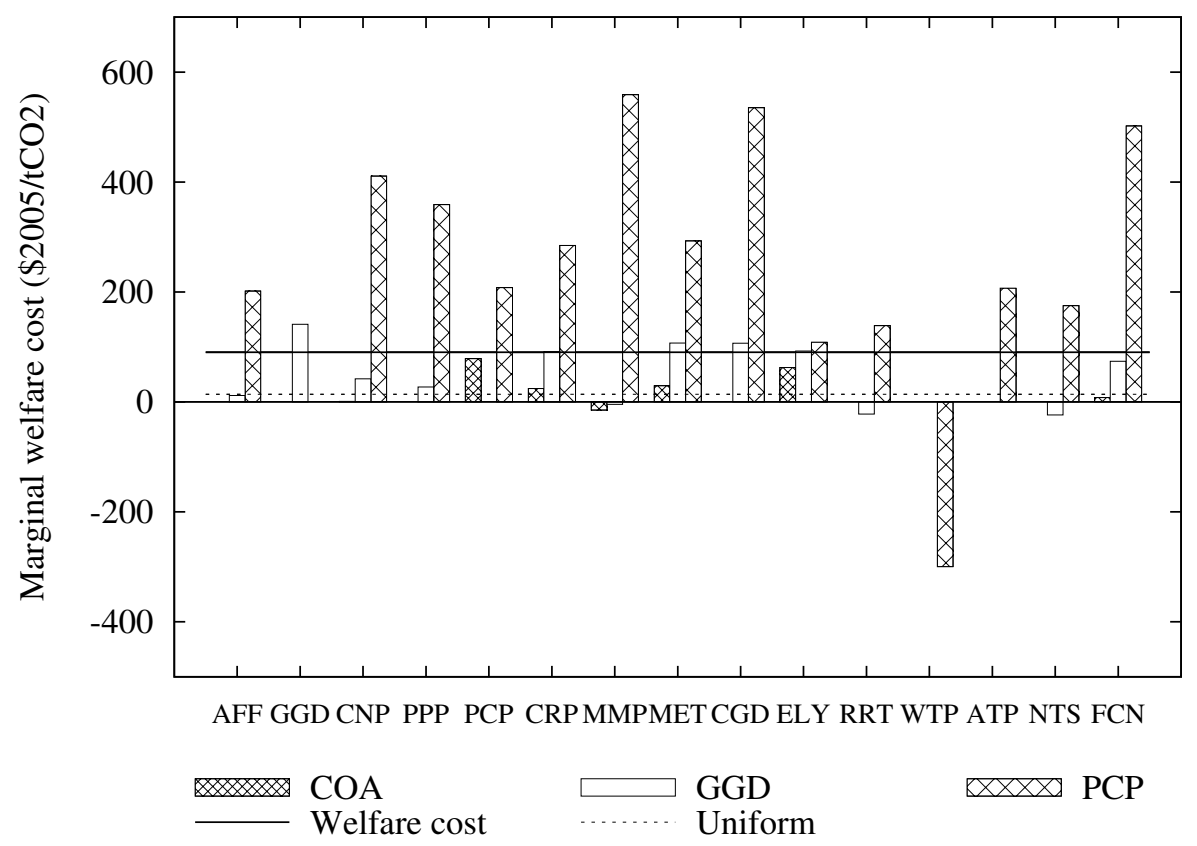

Almost all the marginal welfare costs presented in Figure 1 are higher than the uniform price (dashed line at $14 € / \mathrm{tCO}_{2}$ ), which may seem puzzling at first glance. However, the relevant standard of comparison is not the uniform carbon price itself, but rather its marginal welfare cost. ${ }^{9}$ The marginal welfare cost of the uniform carbon price is $90 € / \mathrm{tCO}_{2}$, as indicated by the solid line in Figure 1. We can see that roughly half of the source-specific marginal welfare costs are below or above this reference.

Optimally differentiated emission prices are calculated by equalising marginal welfare costs across all sources. The result (shown in Figure 2) is, as a rough approximation, a mirror image of Figure 1. Where the marginal welfare costs of the uniform price are high (PCP as an input into many sectors), optimal prices are low (a subsidy of up to $500 € / \mathrm{tCO}_{2}$ ) and vice versa. Overall, it is optimal to subsidise 13 of the 36 sources, almost exclusively PCP. The highest carbon price, however, is for oil as well (1293 $€ / \mathrm{tCO}_{2}$ in WTP). With these optimally differentiated carbon prices, the marginal welfare cost - uniform across sources - turns out to be

\footnotetext{
${ }^{9}$ This distinction is sometimes burred in the literature on carbon pricing. The marginal welfare cost of the carbon price is calculated by increasing the uniform price marginally and dividing the resulting change in welfare by the resulting change in emissions.
} 
Figure 2: Optimally differentiated emission prices

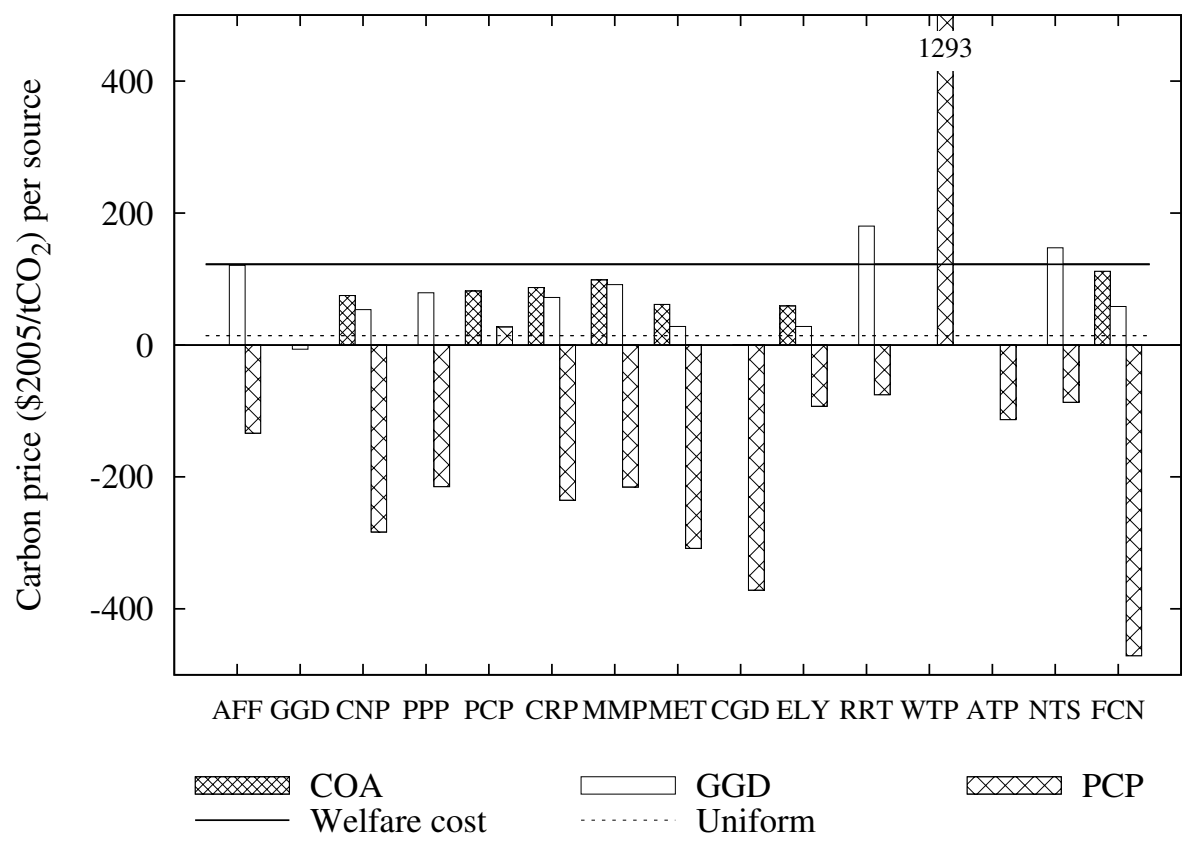

$122 € / \mathrm{tCO}_{2}$ (see the solid horizontal line in Figure 2).

At first glance, it is puzzling that the marginal welfare cost of optimally differentiated carbon prices $\left(122 € / \mathrm{tCO}_{2}\right)$ is higher than that of the uniform price $\left(90 € / \mathrm{tCO}_{2}\right.$ ). How does this concur with the fact that, by construction, the absolute costs of optimally differentiated prices must be lower?

Figure 3 shows total abatement costs for varying levels of emission reductions (up to $30 \%$ ) with either uniform or differentiated emission pricing. Both curves are increasing and convex, as expected. Attaining the target of a $20 \%$ reduction (vertical line) through the introduction of a uniform emission price costs $0.6 \%$ of initial consumption, whereas using differentiated carbon prices instead results in a welfare gain of $0.4 \%$. Implementing an emission-neutral, optimal carbon tax-andtransfer system in the original situation would generate a welfare gain of even $1.2 \%$. Put differently, by using optimally differentiated carbon prices, a $27 \%$ reduction in $\mathrm{CO}_{2}$ emissions can be achieved without a decrease in welfare. As there is a discrete welfare gain by switching from a uniform carbon price to differentiated pricing, it is no contradiction to state that differentiated prices have higher marginal welfare costs. This is demonstrated in Figure 3: for any given level of abatement, the curve 
Figure 3: Abatement costs

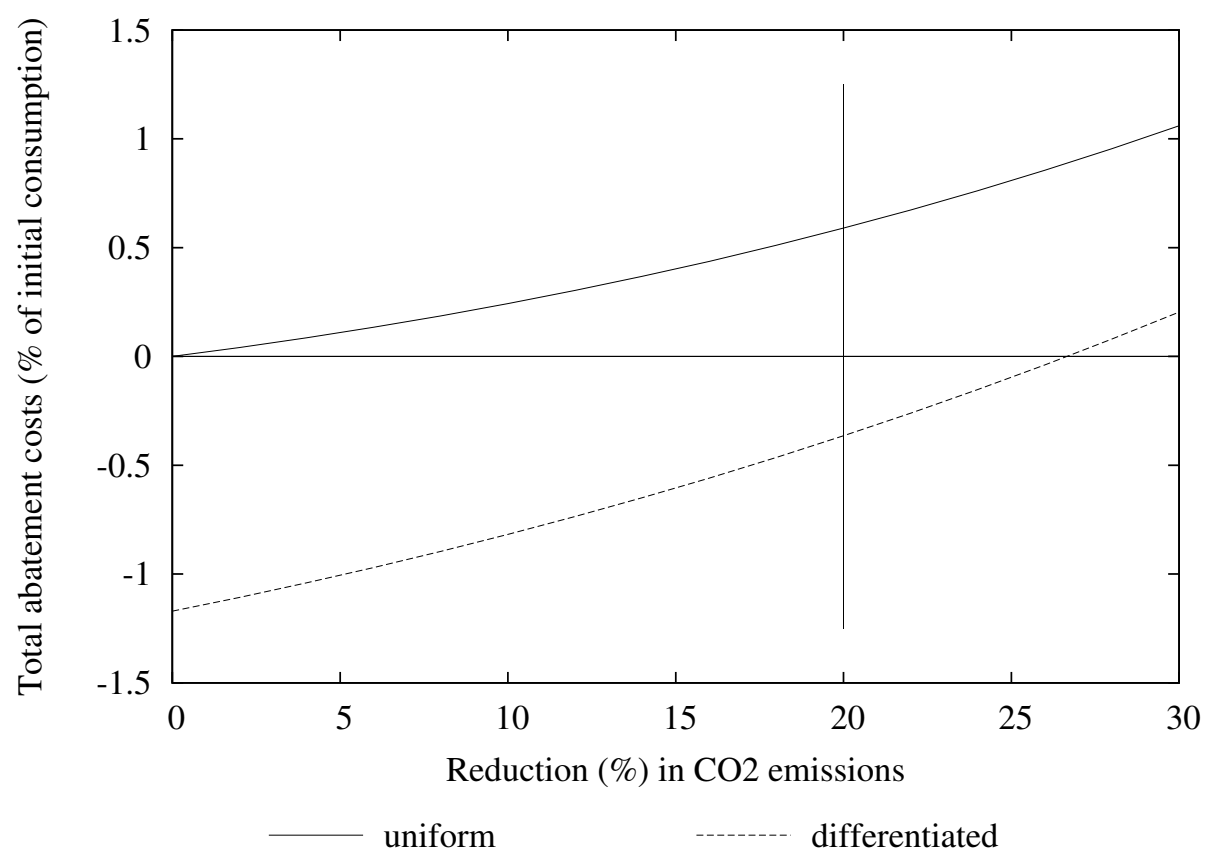

for differentiated prices is slightly steeper than that for the uniform price. In other words, the higher the abatement level, the lower is the welfare gain of an emissionneutral switch from uniform to differentiated pricing.

\subsection{Decomposition}

In the previous subsection, I presented the pattern of optimally differentiated carbon prices derived from the WorldScan model. In a broad sense, we know that preexisting tax distortions and market power in international trade are responsible for the deviation from uniform carbon pricing. However, we do not yet know which particular distortions are responsible for the pattern that emerges in Figure 2. In this subsection, I elucidate the role of specific distortions by performing a series of decomposition exercises. In each of these exercises, all distortions but one are eliminated from the model, and the optimal pattern of differentiated carbon prices is re-calculated. Possible interaction effects notwithstanding, the pattern in Figure 2 should then be interpretable as the sum of the effects of individual distortions. 
Figure 4: Import market power

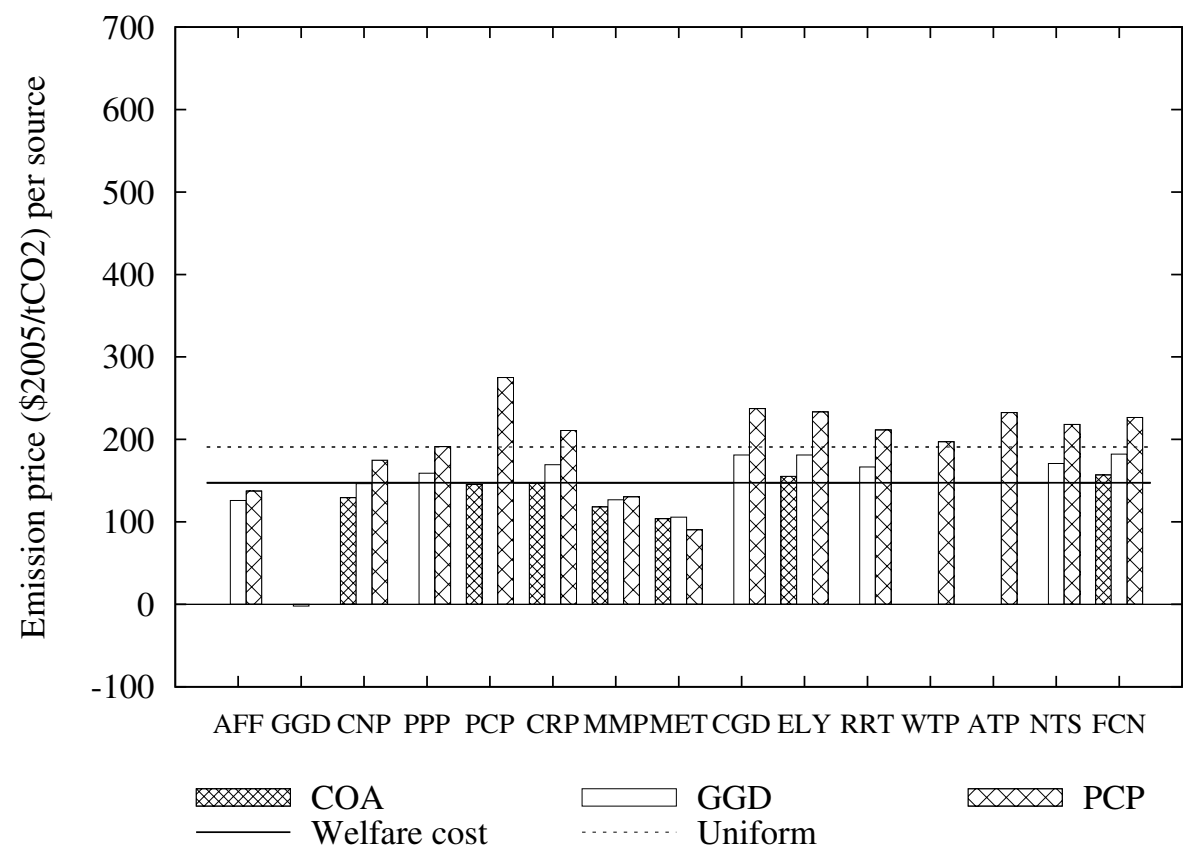

\subsubsection{Market power in international markets}

In the case of market power in international trade, I add the assumption that the $\mathrm{EU}$ is unable to influence international import and export prices. In the model, this is implemented through import and export taxes on trade partners, which are adjusted in order to keep constant the prices incurred by the EU. The EU then acts as a small open economy. ${ }^{10}$ For the case of constant export prices (i.e., only import market power), the resulting pattern of optimal carbon prices is depicted in Figure 4. Overall, the resulting price differentiation is moderate. Energy inputs into the gas (GGD) and metals (MET) sectors are taxed significantly below the average level, while there is also a systematic pattern of pricing emissions from COA lower than from GGD and PCP, but the latter differences are rather small.

Two general features in Figure 4 deserve attention. First, the uniform carbon price necessary to achieve the $20 \%$ reduction goal is $191 € / \mathrm{tCO}_{2}$, considerably higher than in the base case presented in Section 3.1. The reason for this finding is that

\footnotetext{
${ }^{10}$ Böhringer et al. (2014) use a different decomposition strategy. For eliminating terms-of-trade effects, they assume that the abating region must compensate their trade partners for welfare changes incurred because of climate policy.
} 
Figure 5: Export market power

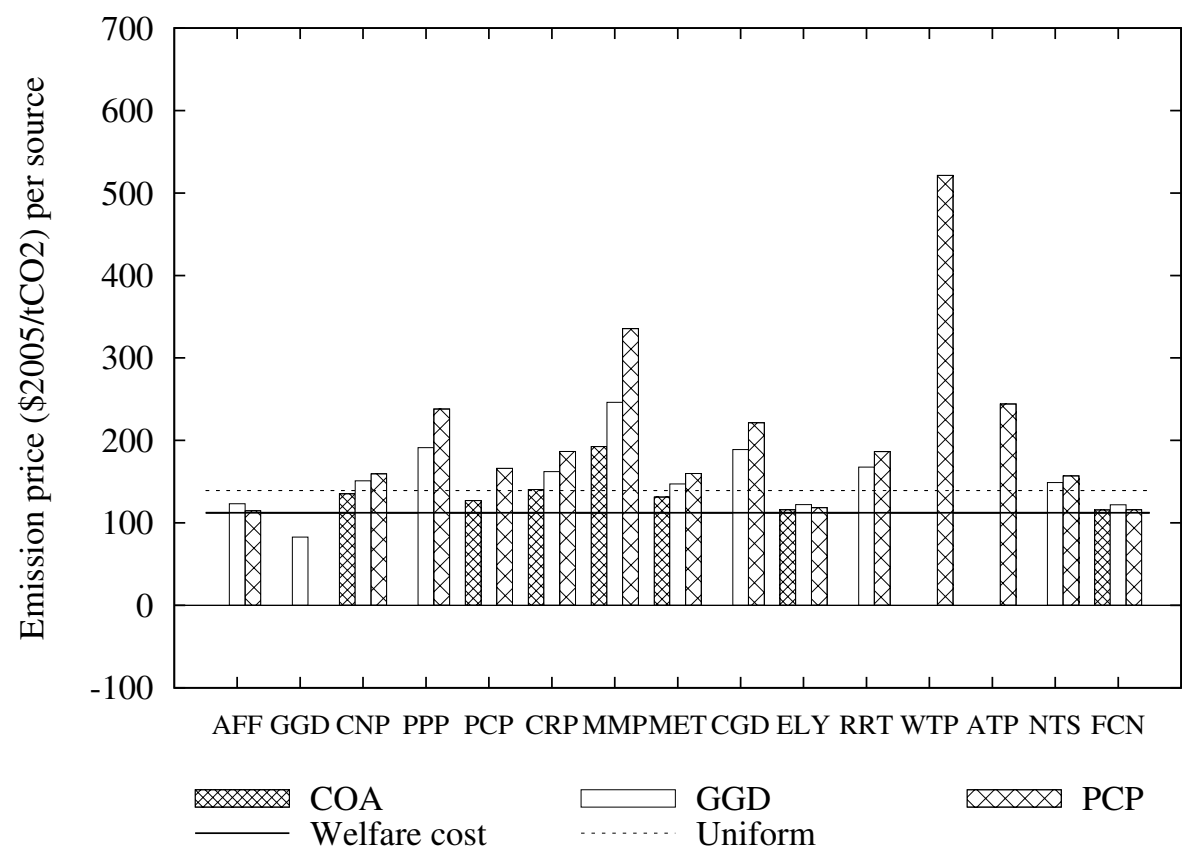

removing all taxes from the model expands the economy in general and emissions in particular. Driving emissions back below the initial level requires additional effort, captured by the carbon price. ${ }^{11}$ Second, in contrast to the base case shown in Section 3.1 , the marginal welfare cost of the uniform carbon price $\left(142 € / \mathrm{tCO}_{2}\right.$, not shown in the figure) is now below the uniform price. This is the direct consequence of the market power in import markets. Market power means that carbon prices not only reduce emissions, but also reduce import prices by reducing import demand. ${ }^{12}$ Again, the marginal welfare costs of optimally differentiated carbon prices $\left(147 € / \mathrm{tCO}_{2}\right)$ are slightly above those of the uniform price.

The mirror image of the case presented in Section 4 is market power in export markets. Again, all pre-existing taxes are set to zero. Further, import prices are fixed at their initial levels through an endogenously adjusting export tax in nonEuropean regions, whereas export prices are free. The resulting pattern of optimal carbon prices is shown in Figure 5.

\footnotetext{
${ }^{11}$ The $20 \%$ reduction goal is still defined with respect to the baseline situation with pre-existing taxes.

${ }^{12}$ This effect is also present in the basic model, but it is overridden by the negative effects of tax distortions.
} 
Compared with market power in import markets (Section 3.2.1), the effects on the differentiation of optimal carbon prices is now significant. Particularly striking is the high tax rate on PCP use in WTP. However, taxes on fuel use in the PPP, MMP and ATP sectors are also considerably above the uniform tax rate. Again, the marginal welfare costs of the uniform price $\left(112 € / \mathrm{tCO}_{2}\right)$ is below this price itself.

\subsubsection{Pre-existing taxes}

Besides market power in international trade, pre-existing taxes form a second set of reasons for deviations from the uniform carbon price. In this section, I focus on three types of taxes: intermediate input taxes, consumption taxes and output taxes. I run model versions that include a preparatory counterfactual where taxes (except for the one focused on) are set to zero and international prices are fixed to eliminate trade effects. The resulting situation is used as the point of departure for climate policy. ${ }^{13}$

Figure 6 shows the consequences of pre-existing intermediate input taxes for the optimal structure of carbon prices. There is one clearly dominating effect, which stems from the intermediate input taxes on refined fuels (PCP). As intermediate input taxes on carbon sources are economically indistinguishable from carbon prices, any difference in these taxes is compensated by optimal carbon prices. ${ }^{14}$ The high subsidies on PCP inputs in Figure 6 can thus be interpreted as a rebate of that part of excise tax payments on transport fuels that exceeds the optimal carbon price level. The only sectors where this does not apply are those where the fuel input is not primarily for transport purposes (i.e. PCP, ELY).

The case of consumption taxes (Figure 7) is straightforward. There are high pre-existing taxes on the private consumption of fuels, in particular on transport

\footnotetext{
${ }^{13}$ The counterfactual situations in which a subset of taxes is set to zero differ from the original model in total emissions. (Normally, as distortions are removed, economic activity and thus emissions would be higher.) Therefore the overall level of carbon prices is not comparable across models. Still, price differentials between sources can be interpreted in the desired way. A second difference across counterfactuals is the overall level of tax receipts. However, all tax receipts are transferred back lump-sum to the representative household so that there is no effect of government spending on the pattern of optimal carbon prices.

${ }^{14}$ This compensation is imprecise, because there are indirect effects of taxes on other intermediate input as well. However, because those effects are small, the overall picture is dominated by the intermediate input taxes on fuels.
} 
Figure 6: Intermediate input taxes

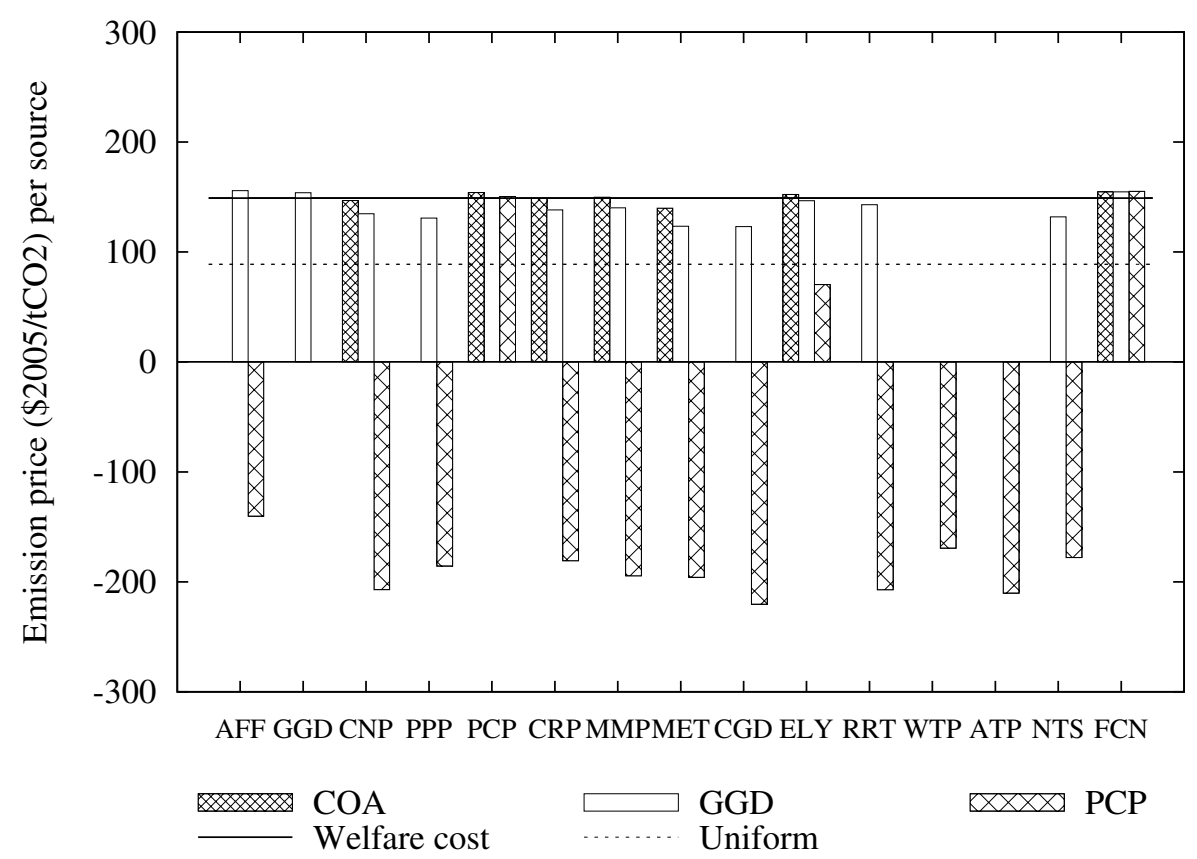

fuels as before. In an optimally differentiated system of carbon prices, this would be reflected by a high compensatory subsidy. There is some spillover on carbon prices in production as well, but this is relatively small.

Finally, we turn to pre-existing output taxes. Again, carbon prices must serve the double role of both regulating emissions and - as far as possible - correcting existing tax distortions. With output taxes, a correction can work in two ways. First, carbon prices on a sectoral input are used to counteract output subsidies in the same sector. This can be illustrated with the case of WTP. The EU output subsidy to WTP in the GTAP data base is $21 \%$ (for comparison: rail and road transport (RRT) $5 \%$ subsidy, air transport (ATP) $2 \%$ tax). Second, carbon prices on fossil fuel inputs counteract output taxes on the production of these fuels. This is reflected in the consistent pattern of carbon prices by fuel in each sector, namely highest for coal and lowest (or even negative) for PCP. Here the respective tax rates from the GTAP database are a $20 \%$ subsidy on COA, $7 \%$ tax on GGD and $12 \%$ tax on PCP. 
Figure 7: Consumption taxes

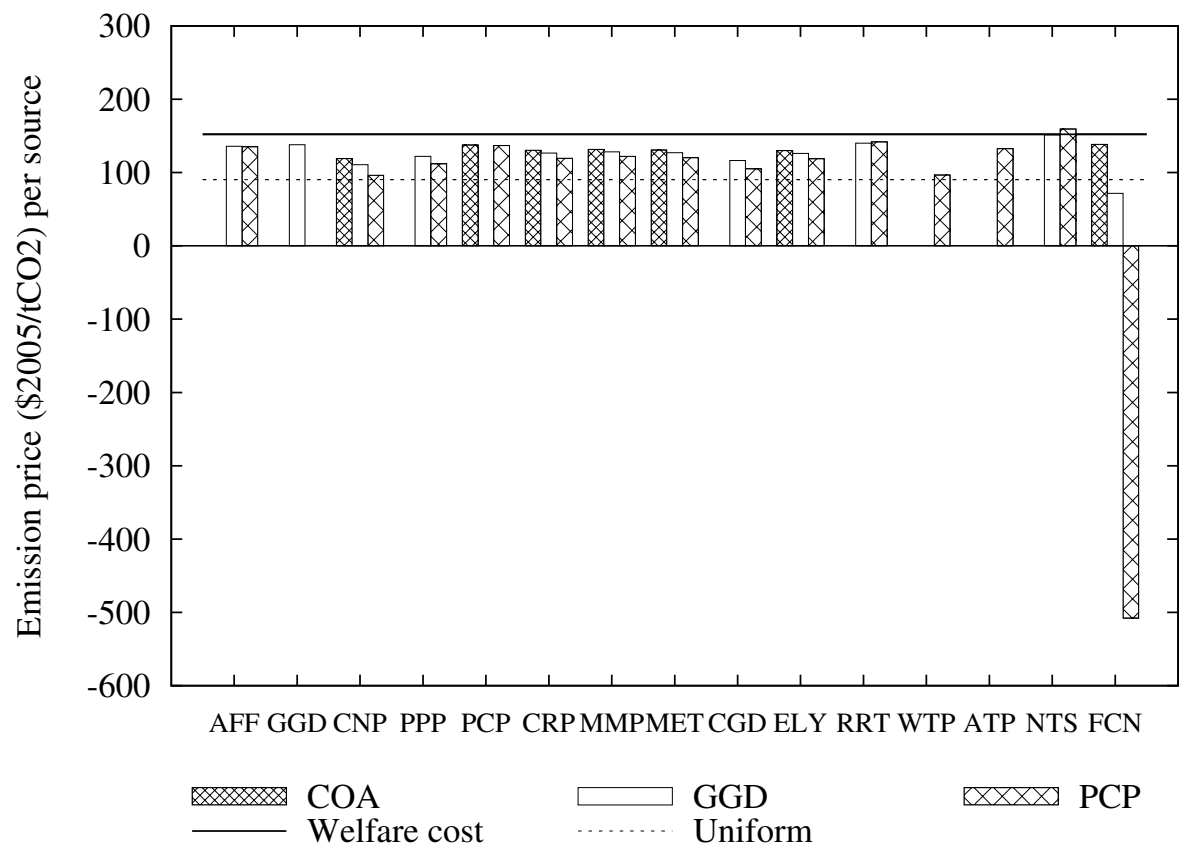

Figure 8: Output taxes

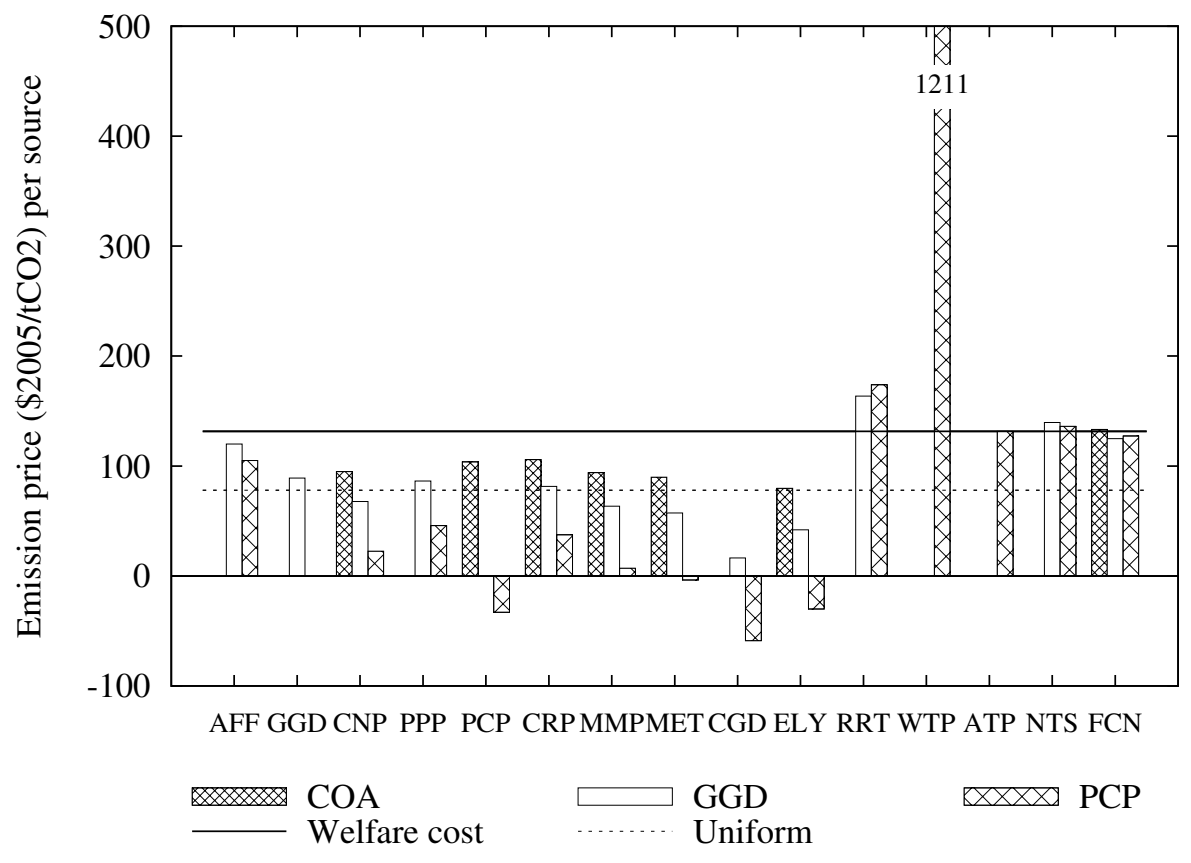


Figure 9: Leakage rates

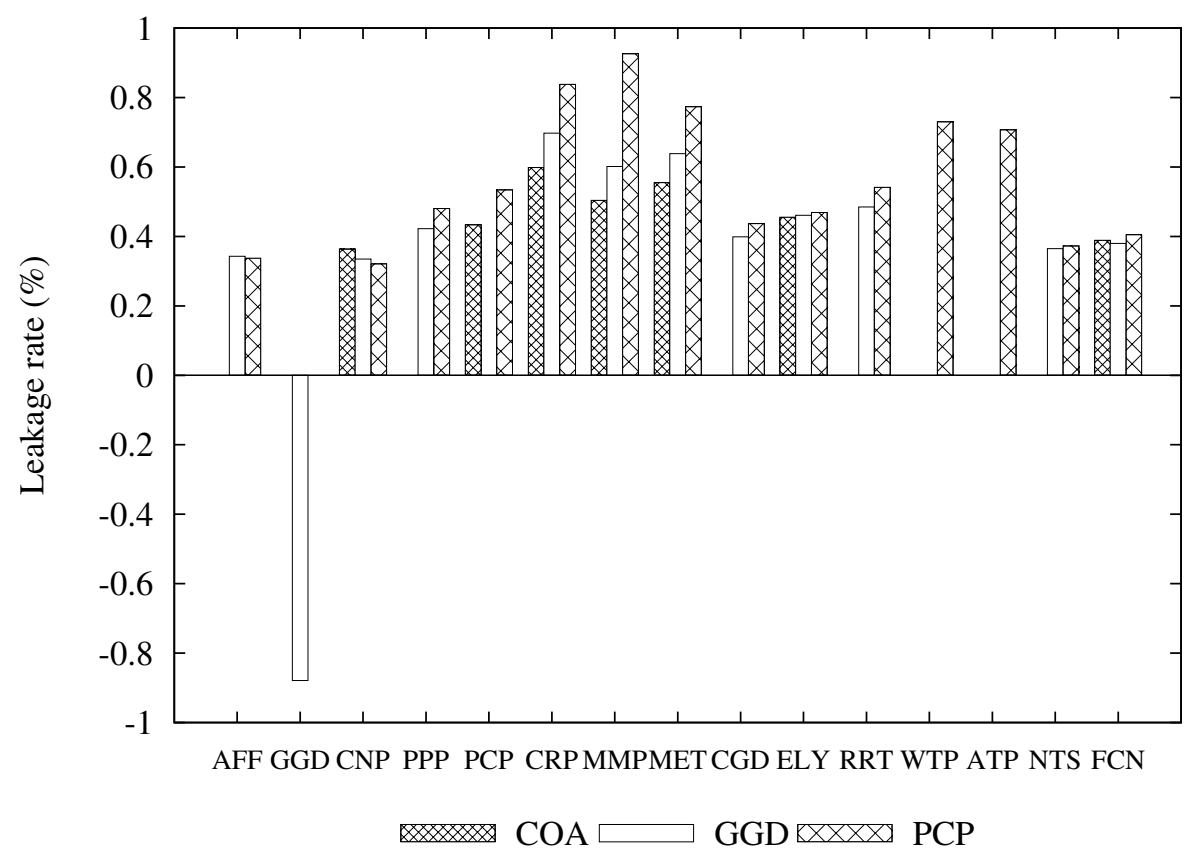

\subsection{Leakage}

The EU climate policy discussed in Sections 3.1 and 3.2 was "domestic" in a narrowly defined sense, namely that the reduction target was expressed in terms of EU emissions only, while the emissions in other regions were ignored. However, carbon leakage is one of the most discussed issues in international climate policy ${ }^{15}$. A natural follow-up step consists therefore in the coverage of emissions from all regions. How do the results change if the reduction target is rather expressed in global emissions? ${ }^{16}$

As a preliminary step, Figure 9 shows marginal leakage rates by source, which have been computed in the following way. We start from the optimally differentiated carbon prices in Figure 2. ${ }^{17}$ Then carbon prices are marginally increased, source by

\footnotetext{
${ }^{15}$ The model comparison study EMF 29 (summarised in Böhringer et al., 2012) covers different aspects of carbon leakage as well as measures designed to counteract it.

${ }^{16} \mathrm{Still}$, the only instrument available is domestic carbon prices, and domestic welfare remains the optimality criterion.

${ }^{17}$ For comparison purposes, Appendix A.2 shows the leakage rates in the situation with a uniform carbon price.
} 
Figure 10: Optimal carbon prices with leakage

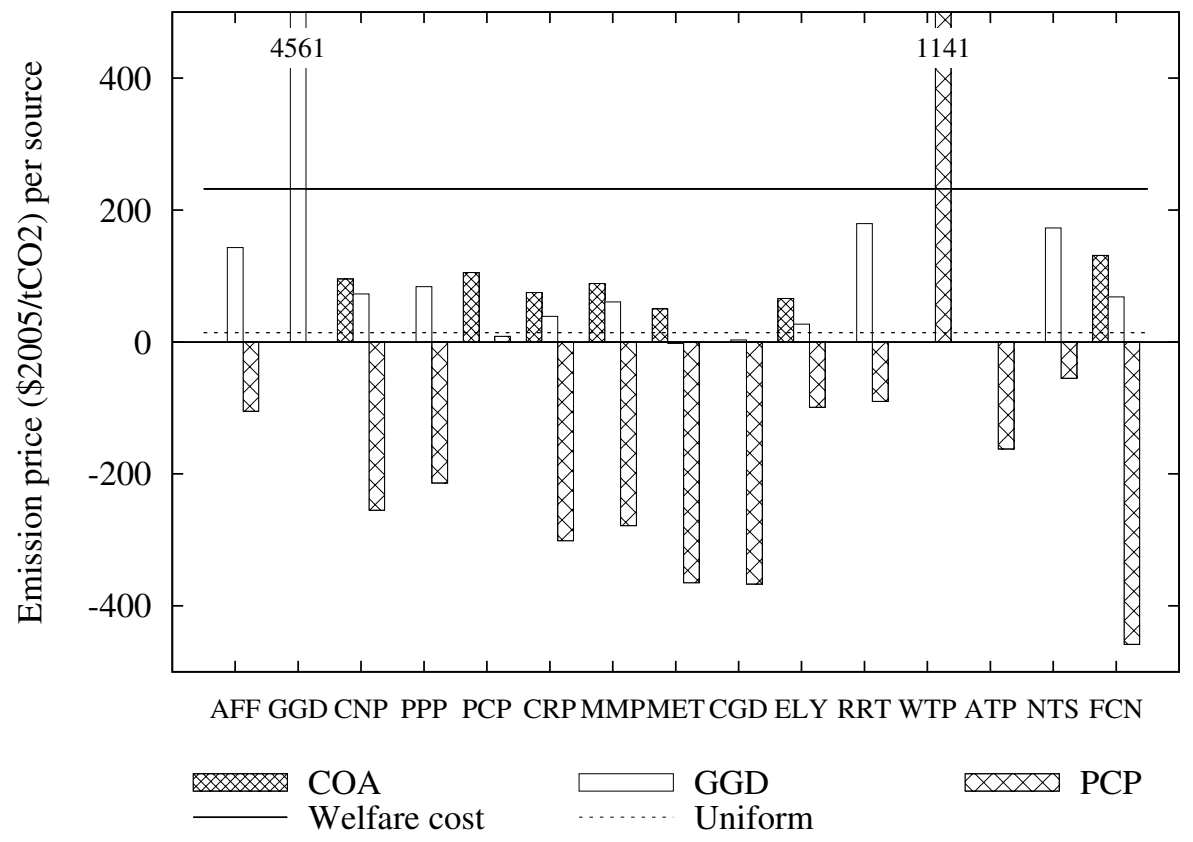

source, and the leakage rate is calculated as

$$
\text { leakage rate }=1-\frac{\text { change in world emissions }}{\text { change in domestic emissions }}
$$

If leakage rates were uniform across sources, the structure of optimally differentiated carbon prices would not change compared with the domestic-centred policy. However, as shown in Figure 9, leakage rates do vary considerably across sources, with a range of between 0.3 and 1, except for one extreme outlier, namely GGD inputs into GGD production, where the leakage rate is almost -1 .

Hence, starting from the domestically optimised carbon prices and targeting world emissions (at the level that results from the price pattern in Figure 2) induces price adjustments. These adjustments are downwards for sources that have aboveaverage leakage rates, and vice versa. ${ }^{18}$ The adjusted prices are shown in Figure 10. However, the quantitative differences with the initial scenario (Figure 2) in which leakage was disregarded, are small for most sources. As a rough pattern, the optimal carbon prices for COA increase slightly because leakage rates for coal are below

\footnotetext{
${ }^{18}$ The average leakage value cannot be pinned down in a straightforward manner. Calculating average leakage would require changing all carbon prices at the same time. As these prices vary (with some even negative), a "uniform" variation cannot be defined without arbitrariness.
} 
average, whereas those for PCP decrease. The outlier in the leakage rates is an outlier in carbon prices as well; indeed, the carbon price for the source GGD in sector GGD increases dramatically.

\section{The role of excise taxes on fuels}

It is clear that we must interpret the modelling results from Section 3 with great caution and avoid rushing into distilling real-world policy recommendations from them. As they stand, these results are explorative and primarily informative about the working mechanisms of models routinely used to evaluate climate policy. ${ }^{19}$ As such they should be seen as an input into an iterative process of model adjustments and interpretation of model results that would ideally result in the critical revision of all model features that are drivers of the structure of optimally differentiated carbon prices.

Take, as an example, the output subsidy in WTP, which has emerged as the main reason for the disproportionally high optimal carbon prices in this sector. Before we may think of translating this result into policy advice, several rounds of checking are necessary. Are the subsidy rates in the GTAP data set reliable? Is there any particularity in the market structure of WTP that might explain this outlier in the data? What policy goal has led to the particularly high subsidy? Can this policy goal be interpreted as the correction of a market distortion, which then must be integrated into the model to ascertain a full picture?

Performing checks of this kind for all aspects of the model that have turned out to be drivers of the simulation results would require a large-scale interdisciplinary project. A huge number of experts would have to be involved in order to provide detailed knowledge on specific sectors such as WTP. Although such an effort is beyond the scope of the present paper, it does address one prominent example as a sensitivity analysis. This exemplifies how model development and modification could be driven by the results presented in Section 3 .

\footnotetext{
${ }^{19}$ Strictly speaking, I can only make claims about the model WorldScan. However, my guess is that other GTAP-based CGE models used to evaluate EU climate policy, such as PACE, GEM-E3, GEMINI-E3 and DART, would produce similar results.
} 
For this analysis, I choose the case of pre-existing taxes on the use of transport fuels; theses taxes trigger large compensatory subsidies on these fuels as an element of optimally differentiated carbon prices. An obvious caveat runs as follows. In the model, pre-existing taxes on fuels are modelled as pure distortions without any underlying rationale except for the generation of government revenue. In the real world, however, different arguments are used to justify fuel excises on economic grounds: (1) internalisation of local environmental damage (air pollution), (2) internalisation of congestion externalities and (3) equivalence financing of road infrastructure (see, e.g., the discussion in Parry and Small, 2005). In all three cases, fuel excises are not a first-best instrument, but it might be argued that they are a reasonable substitute in a situation where a first-best instrument is not readily available.

The model set-up used for the simulations in this section is based on the third argument above. ${ }^{20}$ The fuel excise tax on PCP is now modelled as a joint input into consumption and production. The underlying assumption is that each unit of fuel used requires, as a complement, the construction and repair of roads. The quantity of this joint input is determined by the level of the excise tax in the GTAP data set, and it is assumed to be produced by the NTS sector (which includes construction). ${ }^{21}$

The simulation results show the optimal pattern of differentiated carbon prices if fuel excise taxes are modelled as a joint input only in the transport sectors and in final consumption (Figure 11), or in all non-energy sectors (Figure 12). ${ }^{22}$

Figures 11 and 12 confirm our expectations on the grounds of the distortion argument. Once fuel excise taxes are no longer modelled as a pure distortion, no reason remains to neutralise them by means of negative carbon prices. The carbon prices of PCP use are now much more in line with those of other fuels, except for the sectors in which the fuel excise tax has not been replaced by a joint input.

\footnotetext{
${ }^{20}$ The other two arguments are more difficult to model because they involve externalities. My guess, however, is that the consequences for the outcome would differ little. The only relevant aspect in the present context is that the fuel excise is no longer distortive regardless of the compensating mechanism.

${ }^{21}$ In order to keep the total output of the NTS sector unchanged with respect to the simulations in Section 3 I have introduced a compensatory input tax on NTS for all other uses than road construction work.

${ }^{22}$ The choice between the scenarios in Figures 11 and 12 would require an answer to the question of whether PCP inputs into non-transport sectors are actually fuels for transport services that have not been outsourced to the transport sector (as assumed in Figure 12). This cannot be resolved without extensive data work, if it can be resolved at all.
} 
Figure 11: Optimal prices with the alternative modelling of excise taxes (1)

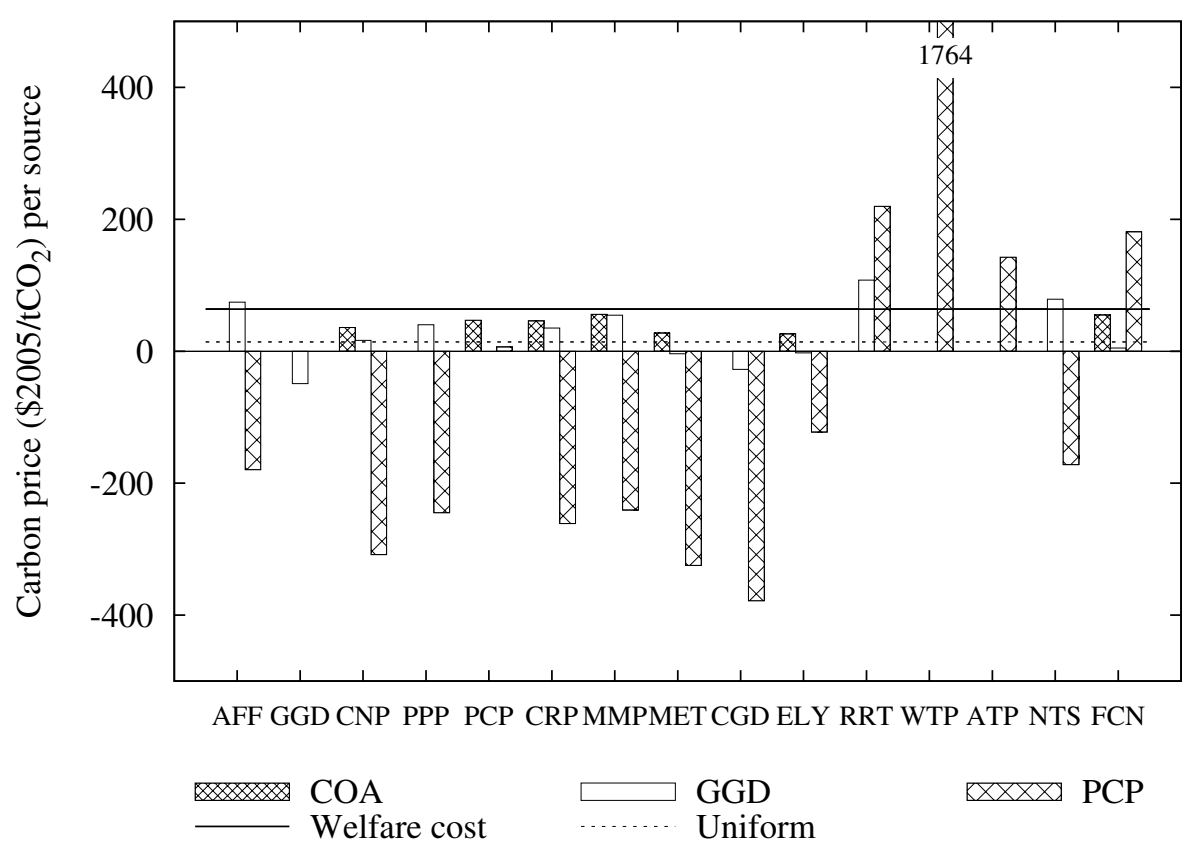

Figure 12: Optimal prices with the alternative modelling of excise taxes (2)

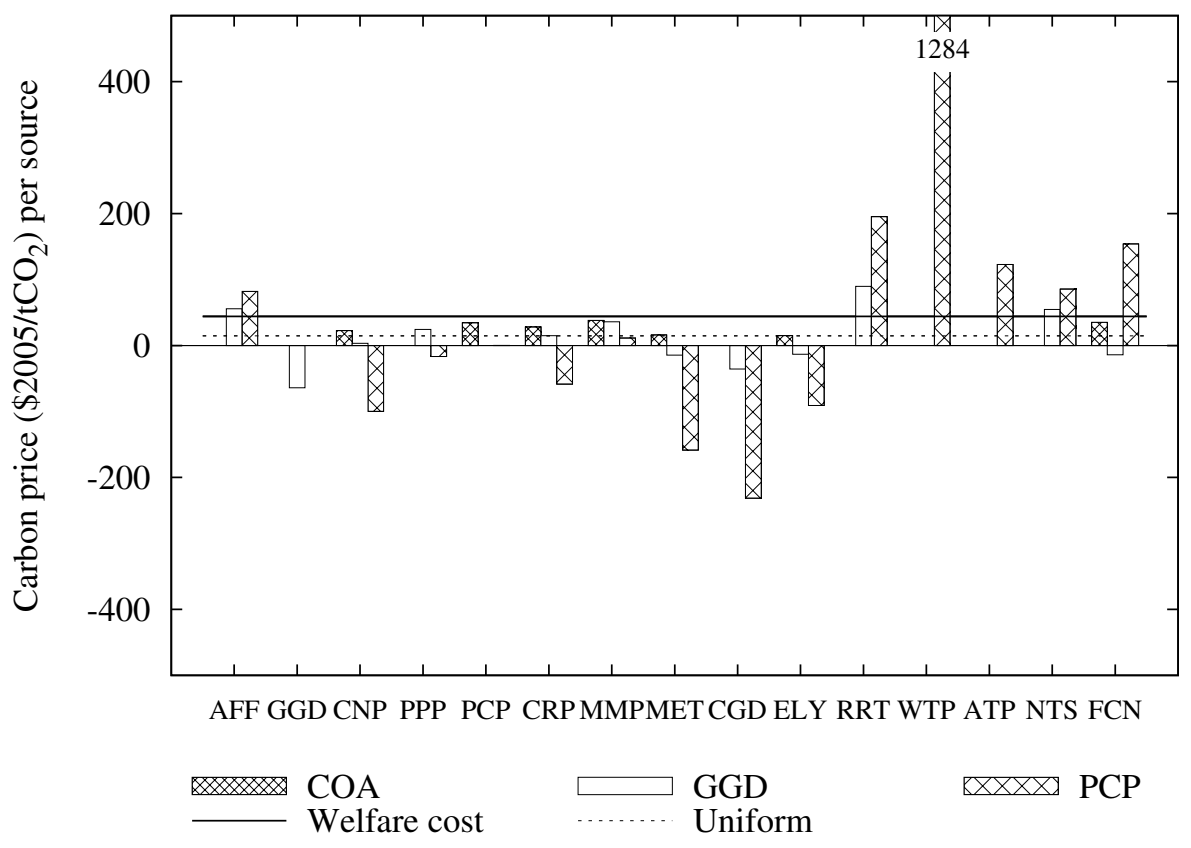




\section{Conclusions}

Economic thought on climate policy as an instance of environmental regulation is strongly dominated by the principle of a uniform carbon price. In stylised models that contain no further distortions, a uniform carbon price can be identified as the most appropriate instrument to equalise marginal abatement costs across sources. This approach inspires environmental economists to advocate emission trading schemes that have maximum scope, allowing for as much "where", "what" and "when" flexibility as possible.

Economists realise that the principle of uniform carbon pricing breaks down in a "second-best" world with other pre-existing distortions such as taxes or market power in domestic and international markets. ${ }^{23}$ Nevertheless, the predominating implicit assumption is that climate policy should not react to this by differentiating carbon prices by source. A single study (Böhringer et al., 2014) treats this assumption as hypothesis, which is tested using a CGE model and confirmed. However, the setup of that study restricts carbon prices differentiation to two prices, one for the energy-intensive sectors and one for the rest of the economy.

By contrast, the simulations in the present paper show that uniform, or almost uniform, carbon prices are not the typical outcome of a standard CGE model when distortions through taxes and international trade are taken into account and separate treatment of all sources is allowed for. In this set-up, welfare-maximising differentiated carbon prices in an EU-only climate policy (reduction in $\mathrm{CO}_{2}$ emissions by $20 \%$ in 2020) in WorldScan can be characterised as follows:

- The optimal pattern of carbon prices is highly differentiated, ranging from almost prohibitive taxes to high subsidies (with a range of more than 1700 euros per ton of $\mathrm{CO}_{2}$ ).

- The welfare gain from switching from a uniform price to optimally differentiated prices is enormous, equivalent to a $27 \%$ emission reduction for free.

\footnotetext{
${ }^{23}$ However, the best-known discussion about the second-best characteristics of environmental levies (a possible "double dividend" from the interaction of environmental and labour market distortions; see Bovenberg (1999) for an overview) is not about the structure but rather about the level of taxes.
} 
- The most important drivers of carbon price differentiation are market power in export markets and taxes on consumption, intermediate inputs and domestic outputs.

- By contrast, market power in import markets and other taxes (tariffs, taxes on investment and income) are less important.

- Accounting for carbon leakage to non-coalition regions leads to considerable shifts in the pattern of optimally differentiated prices, but it does not change the conclusion that differentiation is highly desirable.

It cannot be stressed enough that these model results are not necessarily real-world features. They must therefore not be misunderstood as implicit policy advice. However, they have been generated with a model that is, variations in a number of details notwithstanding, representative of the class of the CGE models routinely used to evaluate climate policy options. Therefore, the effects that drive the results in the present paper are likely also to co-determine the results of other CGE studies, even though they have not been focused upon before. The results thus confront economists that continuously apply these models to ever-varying versions of climate policy with the following questions: do we believe that pre-existing market distortions actually produce such a large variation in the pattern of optimally differentiated carbon prices? Or are we convinced that the principle of a uniform carbon price should remain an important driver of the results nevertheless?

The present paper only raises these questions, but cannot answer them. An encompassing answer would require a huge interdisciplinary effort, scrutinising each of the distortions present in the model. What the paper does show, however, is a possible approach if researchers are convinced that optimal carbon prices are not as diverse as implied in the model. Once we are prepared to view pre-existing taxes not as pure distortions, but as instruments that (partially) internalise externalities, this has direct consequences for the pattern of optimally differentiated carbon prices. For the concrete example of fossil fuel excises on intermediate inputs and consumption, the paper shows that modelling them as joint inputs (to be interpreted as road construction complementary to transport services), instead of taxes, eliminates the subsidy peaks in the pattern of optimally differentiated carbon prices. 
While this revision of modelling pre-existing distortions is cumbersome, it is indispensable. The barrier to making carbon price differentiation an instrument of actual climate policy must be set at a high level. After all, carbon price differentiation is likely to bring high policy costs with it. The process of actually determining the optimal pattern of differentiation would certainly attract lobby groups, each with their own model showing - surprise! - that the carbon price in their own sector must be particularly low. This is an undesirable situation, and thus the level of welfare gains required to justify entering a regime of this sort should be high. However, if the welfare gains to be reaped are even close to those calculated in the simulations of this paper, namely equivalent to a $27 \%$ emission reduction for free, this option should not be easily dismissed.

\section{Literature}

Badri, N.G. and T.L. Walmsley (2008), Global trade, assistance, and production: The GTAP 7 data base, Center for Global Trade Analysis, Purdue University.

Baumol, W.J. and D.F. Bradford (1970), Optimal departures from marginal cost pricing, American Economic Review 60, 265-283.

Boeters, S. and J. Koornneef (2011), Supply of Renewable Energy Sources and the Cost of EU Climate Policy, Energy Economics 33, 1024-1034.

Böhringer, C. and V. Alexeeva-Talebi (2012), Unilateral climate policy and competitiveness: Economic implications of differential emission pricing, The World Economy 35, DOI: 10.1111/j.1467-9701.2012.01470.x.

Böhringer, C., T.F. Rutherford and R.S.J. Tol (2009), The EU 20/20/2020 targets: An overview of the EMF 22 assessment, Energy Economics, Supplement 2, "International, U.S. and E.U. Climate Change Control Scenarios: Results from EMF 22", 268-273.

Böhringer, C., A. Lange and T.F. Rutherford (2014), Optimal emission pricing in the presence of international spillovers: Decomposing leakage and terms-of-trade motives, Journal of Public Economics 110, February 2014, 101-111. 
Böhringer, C., E.J. Balistreri and T.F. Rutherford (2012), The role of border carbon adjustment in unilateral climate policy: Overview of an Energy Modeling Forum study (EMF 29), Energy Economics 34, Supplement 2 "The Role of Border Carbon Adjustment in Unilateral Climate Policy: Results from EMF 29", S97-S110.

Bovenberg, A.L. (1999), Green tax reform and the Double Dividend: An updated Reader's Guide, International Tax and Public Finance 6, 421-443.

Ferris, M.C., S.P. Dirkse and A. Meeraus (2005), Mathematical programs with equilibrium constraints: automatic reformulation and solution via constrained optimization, in: Applied general equilibrium modeling. In honor of Herbert Scarf, editors: T.J. Kehoe et al., Cambridge University Press, 67-93.

Hoel, M. (1996), Should a carbon tax be differentiated across sectors?, Journal of Public Economics 59, 17-32.

Lipsey, R.G. and K. Lancaster (1956), The general theory of second best, The Review of Economic Studies 24, 11-32.

Lejour, A., P. Veenendaal, G. Verweij and N. van Leeuwen (2006), WorldScan: A model for international economic policy analysis, CPB Document 111, Netherlands Bureau for Economic Policy Analysis, Den Haag.

Markusen, J. (1975), International externalities and optimal tax structures, Journal of International Economics 5, 15-29.

OECD (2008), OECD Environmental Outlook to 2030, OECD, Paris.

Paltsev, S., J.M. Reilly, H.D. Jacoby, R.S. Eckaus, J. McFarland, M. Sarofim, M. Asadoorian and M. Babiker (2005), The MIT emissions prediction and policy analysis (EPPA) model: Version 4, MIT Joint Program on the Science and Policy of Global Change Report 125.

Parry, I.W.H. and K.A. Small (2005), Does Britain or the United States have the right gasoline tax?, American Economic Review 95, 1276-1289. 
Rutherford, T.F. (1995), Extensions of GAMS for complementarity problems arising in applied economic analysis, Journal of Economic Dynamics and Control 19, 1299-1324. 


\section{Appendices}

\section{A.1 Sensitivity: different baseline assumptions}

The simulations in an earlier version of this paper were based on a different set of baseline assumptions (see Table 6). After switching to the newer baseline (see Table 5 ) it turned out that the baseline assumptions have hardly any consequences for the pattern of optimally differentiated carbon prices (Figure 13; compare with Figure 2). In contrast to the structural modelling assumptions crucial for the model results (see Section 4), the baseline assumptions are thus of minor importance.

Table 6: Alternative baseline in 2020: Quantities and prices

\begin{tabular}{lcc}
\hline \hline Economic indicators & $\begin{array}{c}\text { 2020 value as a } \\
\text { multiple of 2004 }\end{array}$ & $\begin{array}{c}\text { Yearly growth } \\
\text { 2004-2020 (\%) }\end{array}$ \\
\hline Population & 1.060 & 0.4 \\
Real GDP & 1.091 & 0.5 \\
Fossil energy use & 0.835 & -1.1 \\
$\quad$ Oil & 0.827 & -1.2 \\
$\quad$ Natural gas & 0.709 & -2.1 \\
$\quad$ Coal & 1.032 & 0.2 \\
Electricity use & 1.344 & 1.9 \\
CO, emissions & 0.854 & -1.0 \\
Fossil energy intensity & 0.756 & -1.7 \\
Emission intensity & 1.023 & 0.1 \\
Fossil energy prices & & \\
$\quad$ Oil & 2.338 & 5.5 \\
$\quad$ Natural gas & 2.370 & 5.5 \\
Coal & 1.376 & 2.0 \\
\hline \hline
\end{tabular}

\section{A.2 Leakage rates}

The leakage rates shown in Figure 9 have been calculated based on optimally differentiated carbon prices. For comparison purposes, Figure 14 shows the leakage rates with a uniform carbon price. The general pattern is similar. However, with a uniform carbon price the spread among leakage rates is larger. For one source, PCP 
Figure 13: Optimally differentiated emission prices (alternative baseline)

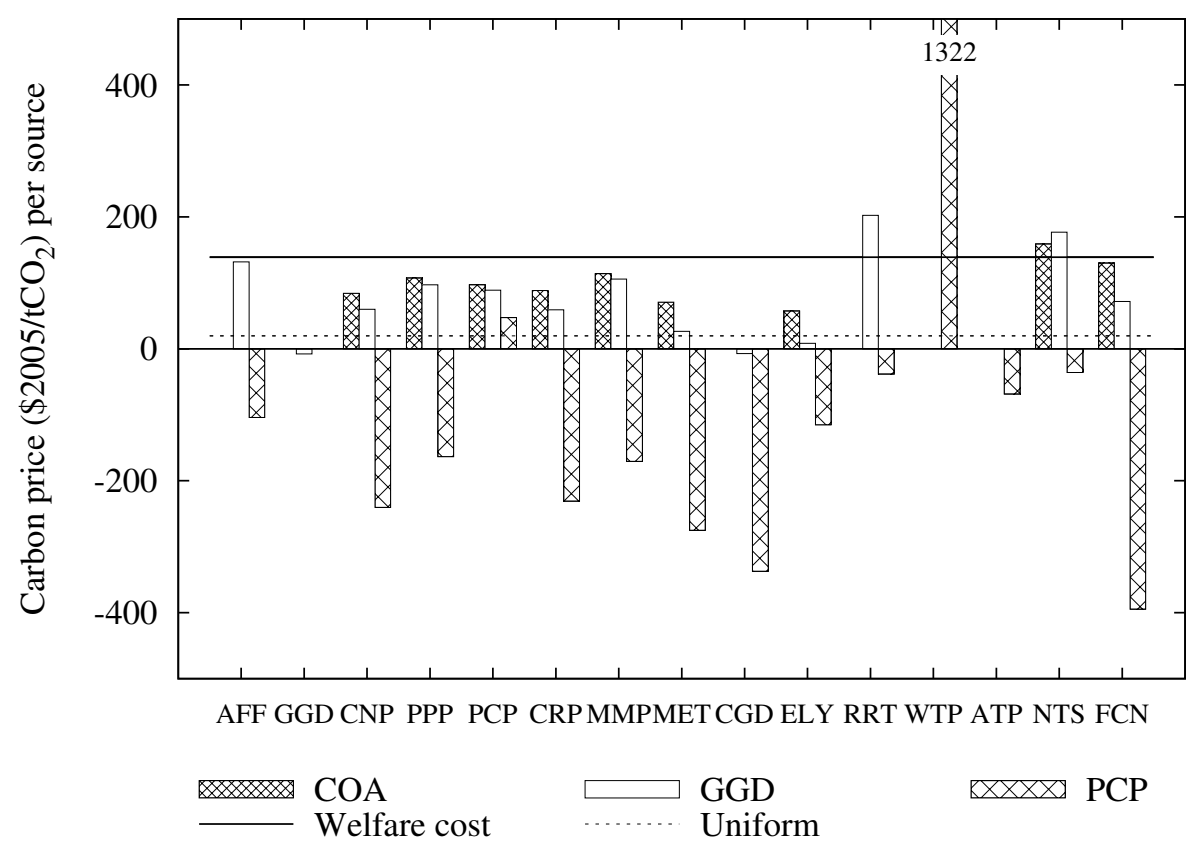

Figure 14: Leakage rates (uniform carbon price)

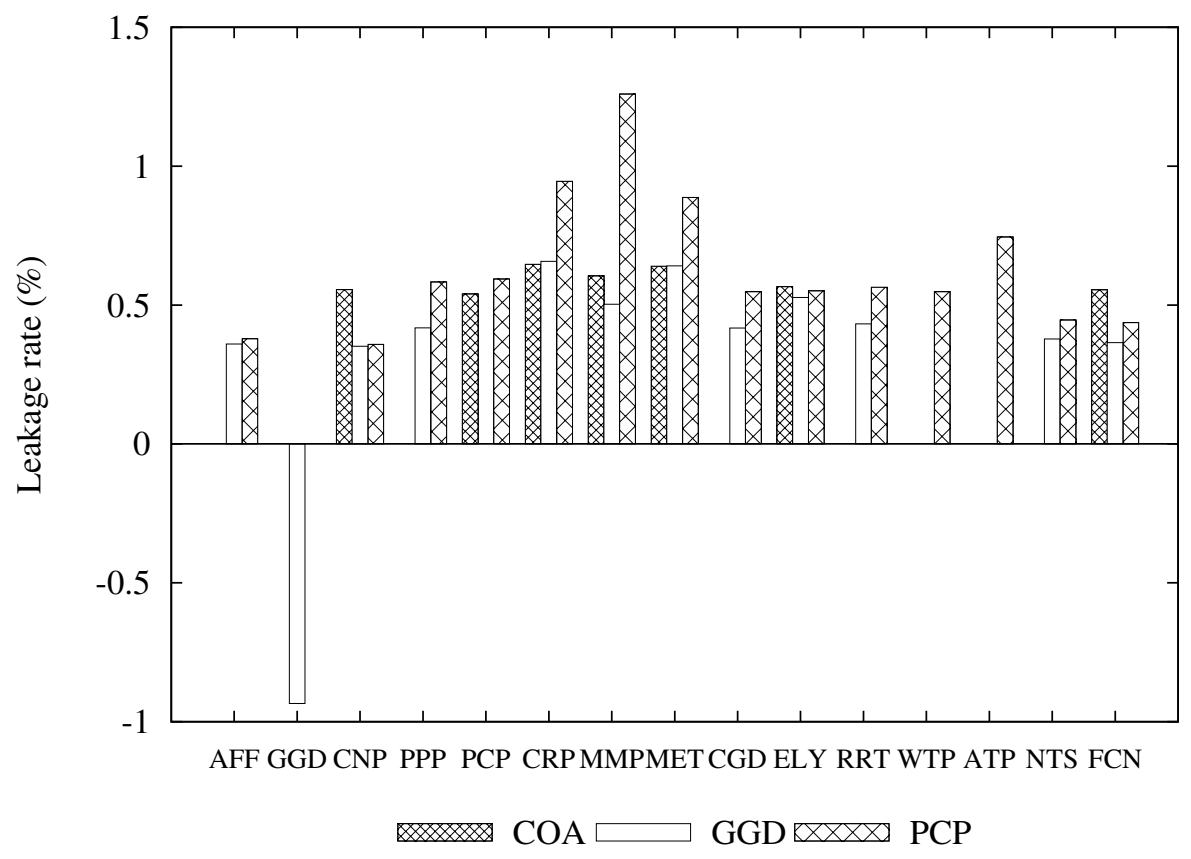

in MMP, leakage even exceeds 100\%. Differentiating carbon prices apparently also leads to a reduction in the spread of leakage rates. 


Publisher:

CPB Netherlands Bureau for Economic Policy Analysis

P.O. Box $80510 \mid 2508$ GM The Hague

$\mathrm{T}(070) 3383380$

July 2014 | ISBN 978-90-5833-653-8 